\title{
Dietary alterations modulate the microRNA 29/30 and IGF-1/AKT signaling axis in breast Cancer liver metastasis
}

\author{
Anuradha A. Shastri ${ }^{1}$, Anthony Saleh², Jason E. Savage², Tiziana DeAngelis ${ }^{1}$, Kevin Camphausen ${ }^{2}$ and \\ Nicole L. Simone ${ }^{1 *}$
}

\begin{abstract}
Background: Metastatic cancer is incurable and understanding the molecular underpinnings is crucial to improving survival for our patients. The IGF-1/Akt signaling pathway is often impaired in cancer leading to its progression and metastases. Diet modification is known to alter the IGF-1/Akt pathway and affect the expression of microRNA involved in tumor initiation, growth and metastases. Liver metastases are one of the most common type of metastases in breast and colon cancer. In the present study, we looked at the effect of diet modification on the expression of microRNA in normal liver and liver with breast cancer metastases using in vivo model.
\end{abstract}

Methodology: 6-month-old C57BL/6 J mice were put on either an ad libitum (AL) diet, or 40\% calorie restricted (CR) diet or were fasted for $24 \mathrm{~h}$ (FA) before sacrifice. MicroRNA array analysis, western blot and qRT-PCR were performed using liver tissue to compare the treatment groups. A breast cancer model was also used to study the changes in microRNA expression in liver of a group of BALB/c mice orthotopically injected with $4 \mathrm{~T} 1$ cells in the mammary fat pad, put on either an AL or 30\% CR diet. Liver and primary tumor tissues were used to perform qRT-PCR to compare the treatment groups.

Results: MicroRNA array analysis showed significant changes in miRNA expression in both CR and FA conditions in normal liver. Expression of miR-29 and miR-30 family members was increased in both CR and FA. Western blot analysis of the normal liver tissue showed that CR and FA downregulated the IGF-1/Akt pathway and GRT-PCR showed that the expression of miR-29b, miR-29c, miR-30a and miR-30b were increased with CR and FA. Liver tissue collected from mice in the breast cancer model showed an increase in expression of miR-29b, miR-29c and miR-30b while tumor tissue showed increased expression of miR-29c, miR-30a and miR-30b.

Discussion: Members of the miR-29 family are known to target and suppress IGF-1, while members of the miR-30 family are known to target and suppress both IGF-1 and IGF-1R. In the present study, we observe that calorie restriction increased the expression of miR-29 and miR-30 in both the normal liver as well as the liver with breast cancer metastases. These findings suggest that dietary alterations may play a role in the treatment of liver metastasis, which should be evaluated further.

Keywords: Liver, Diet, Calorie restriction, Fasting, microRNA, Insulin signaling, Breast cancer metastases

\footnotetext{
* Correspondence: nicole.simone@jefferson.edu

1 Department of Radiation Oncology, Sidney Kimmel Cancer Center at

Thomas Jefferson University, Philadelphia, PA, USA

Full list of author information is available at the end of the article
}

(c) The Author(s). 2020 Open Access This article is licensed under a Creative Commons Attribution 4.0 International License, which permits use, sharing, adaptation, distribution and reproduction in any medium or format, as long as you give appropriate credit to the original author(s) and the source, provide a link to the Creative Commons licence, and indicate if changes were made. The images or other third party material in this article are included in the article's Creative Commons licence, unless indicated otherwise in a credit line to the material. If material is not included in the article's Creative Commons licence and your intended use is not permitted by statutory regulation or exceeds the permitted use, you will need to obtain permission directly from the copyright holder. To view a copy of this licence, visit http://creativecommons.org/licenses/by/4.0/ The Creative Commons Public Domain Dedication waiver (http://creativecommons.org/publicdomain/zero/1.0/) applies to the data made available in this article, unless otherwise stated in a credit line to the data. 


\section{Introduction}

Metastatic cancer is associated with disease that has spread beyond its initial site requiring constant treatment to prevent disease progression. Patients will ultimately succumb to metastatic breast cancer from either consequences of the disease or toxicity of treatment including cardiac toxicities and secondary malignancies. Liver metastases are among the most common types of metastases, representing more than $50 \%$ of breast and colorectal metastases, and are inescapably fatal $[1,2]$. Few treatments exist to restrain these metastases, emphasizing the importance of identifying the novel molecular mechanisms driving them. The liver is a critical nutrient sensor and is rich in metabolic processes affected by dietary alterations evaluated in prior works [3-5], but has not yet been examined in the context of metastatic cancer. Caloric restriction (CR) has previously been shown to play a role in decreasing both primary tumor growth and metastases [6], and short-term or intermittent fasting have been shown to reproduce many of the physiologic changes observed during CR, such as slowing tumor growth and incidence [7-9]. It therefore follows that dietary alterations may play a role in managing liver metastases.

At the mechanistic level, microRNAs (miRNA), or small non-coding RNAs, play a role in cancer initiation, progression and metastases [10-14] and are altered by dietary interventions like fasting and caloric restriction [15-18]. In the present study, we used in vivo experiments to determine if dietary alterations affect miRNA expression in the normal liver or in liver metastases from breast cancer to identify potential novel targets for breast cancer liver metastases. We report global microRNA expression changes in liver tissue from normal mice fed ad libitum (AL), 40\% CR diet, or following a 24-h fast. Here we show increased expression of miR-29 and miR-30 family members due to these dietary interventions in the normal liver and breast cancer liver metastases models. Multiple members of each of the miRNA family directly target and repress the IGF-1/ IGF-1R signaling axis, which is associated with decreased cancer progression and metastases. Our findings support the use of dietary intervention in treatment and provide a novel targeting strategy for therapies in the future.

\section{Materials and methods}

\section{Mice and dietary regimen}

For the normal mice subjected to ad libitum (AL) feeding or dietary alterations, 15 6-month old C57BL/6 J mice were obtained through the National Institute of Aging (NIA) Aged Rodent Program under two feeding conditions (Charles River) on an Institutional Animal Care and Use Committee (IACUC) approved mouse protocol. One group of 10 mice was fed AL diet, and the remaining 5 mice were fed a calorie restriction (CR) diet of $60 \%$ normal intake. CR was initiated a week after arrival with a $10 \%$ restriction, increased to $25 \%$ restriction the next week, and to $40 \%$ restriction the following week, where it was maintained throughout the life of the animal. All mice were singly housed throughout the experiment and were fed NIH-31 food fortified with an NIA supplement for CR mice. Age-matched AL mice were fasted for $24 \mathrm{~h}$ (FA) before sacrifice.

To assess the effect of diet in a murine breast cancer model, 12-week-old BALB/c mice were acquired from Charles River Laboratories under an IACUC approved protocol at Thomas Jefferson University. At 13 weeks, all mice received orthotopic injections of 50,000 4T1 luciferase-tagged cells (a gift from Patricia Steeg) into the \#4 mammary fat pad. Mice treated with CR were stepped down to $90 \%$ of their baseline chow intake for 5 days, followed by 2 successive $10 \%$ decreases every 5 days until a $30 \%$ total reduction was achieved (LabDiet 5010).

Total RNA purification, array analysis, and real-time PCR AL, CR, and fasted mice were sacrificed; the liver tissues were dissected and immediately placed in RNAlater (Ambion). RNA was isolated from the liver tissue using Trizol (Invitrogen) method. RNA concentration and quality were determined using Nanodrop and quantitative real-time PCR (qRT-PCR) was performed (Applied Biosystems 7500 fast) using the miScript SYBR Green PCR kit and miScript Primer Assay for miR-29 and miR-30 (Qiagen). miRNA levels were normalized to snord68 as an internal control. miRNA microarray analysis was performed by LC Sciences (Houston, TX) on $5 \mu \mathrm{g}$ of total RNA as previously described [19].

\section{Immunoblotting}

Total protein was extracted from $50 \mathrm{mg}$ of RNA-later preserved mouse liver tissue. Tissue was added to $1 \mathrm{~mL}$ of SDS lysis buffer (1\% SDS, $50 \mathrm{mM}$ Tris pH 8.0, $10 \mathrm{mM}$ EDTA, Protease inhibiter (Roche), and Halt Phosphatase Inhibitor (Thermo Scientific) in a lysing matrix D tube (MP Biomedicals). Tissue was homogenized using manufacturer's suggested settings for a FastPrep-24 machine (MP Biomedicals). Samples were sonicated using a probe sonicator four times for $5 \mathrm{~s}$ each on ice and heated at $70{ }^{\circ} \mathrm{C}$ for $30 \mathrm{~min}$ with mixing. Lysates were cleared by centrifugation at $14,000 \times \mathrm{g}$ for $10 \mathrm{~min}$ at $4{ }^{\circ} \mathrm{C}$. Protein concentration was determined using the BCA Protein Assay (Thermo Scientific). $40 \mu \mathrm{g}$ of total protein was subjected to SDS-PAGE on a $4-12 \%$ gradient Bis-Tris gel (Invitrogen). Protein was transferred to a $0.2-\mu \mathrm{m}$ PVDF membrane using the XCell transfer system (Invitrogen). Western blots were performed using the following antibodies: IGF-1 (Santa Cruz Biotechnology), IGF-1Rß (Cell Signaling Technology), phospho-IGF-1R tyrosine 1165/ tyrosine 1166 (Sigma), IRS1 (Cell Signaling Technology), 
a

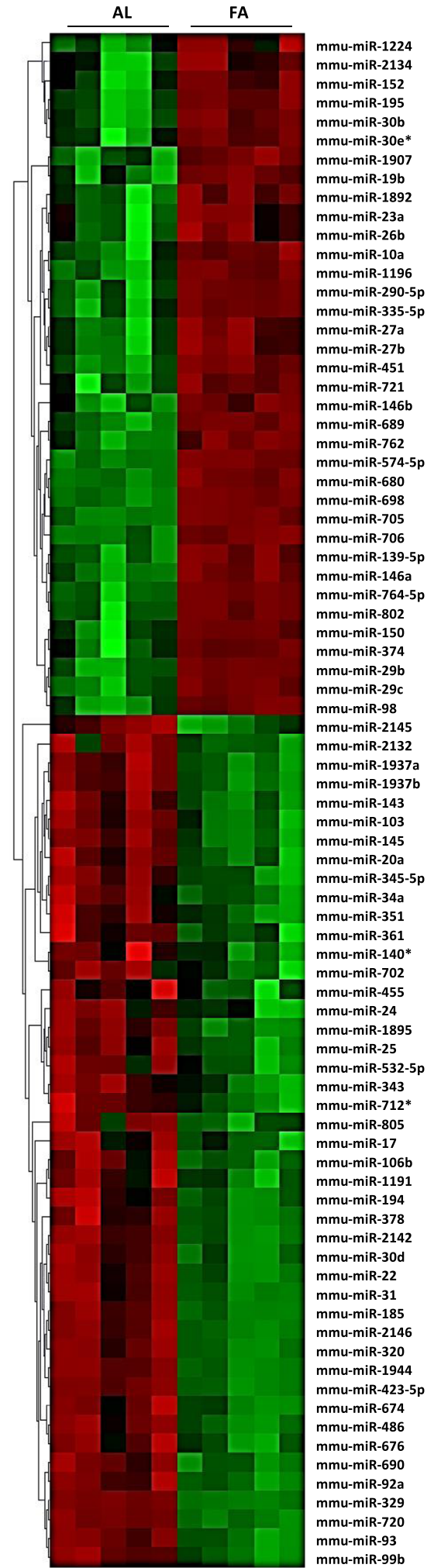

b

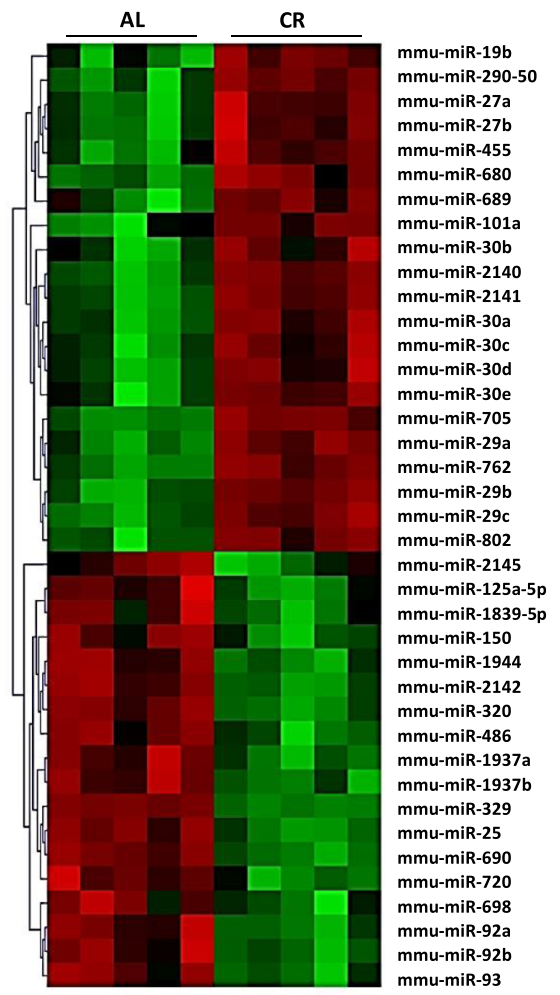

c

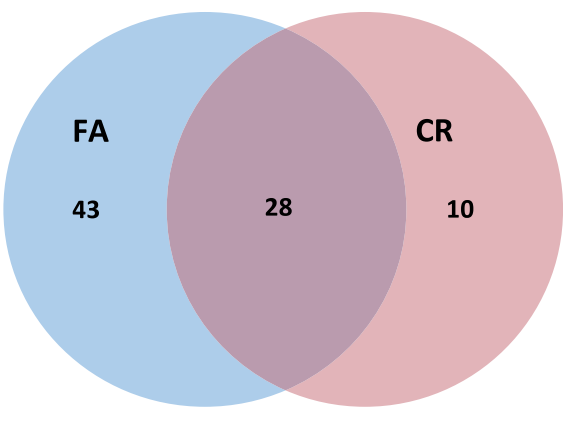

Fig. 1 (See legend on next page.) 
(See figure on previous page.)

Fig. 1 Diet modification changes the expressions of multiple microRNA in normal liver tissue of mice. MicroRNA expression patterns were detected by microarray from total RNA purified from normal liver tissue of C57BL/6 J mice following Ad. Libitum (AL) diet, 40\% Caloric restriction (CR) diet or a 24-h fast (FA). a Heat map clustering of significantly changed microRNAs in normal livers of mice on AL or FA diet. $\mathbf{b}$ Heat map clustering of significantly changed microRNAs in normal livers of mice on AL or CR diet. c Venn diagram showing liver microRNA expression overlap between CR and FA diet groups

pan AKT (Cell Signaling Technology), phospho-AKT serine 473(Cell Signaling Technology), GAPDH (Santa Cruz Biotechnology).

\section{Bioinformatics and statistics}

miRNA arrays were performed on 3 samples for each condition. Significance between normalized expressions from array samples was determined using Student's $t$-test and $p<0.02$. Data from the microarray experiments were collected and analyzed in accordance with the MIAME guidelines. MicroRNA expression profiles were analyzed using IPA software 9 core analysis function and microRNA target filter. miRNA target prediction was performed using Targetscan 5.1 and PICTAR. Unless otherwise stated, data represent the mean of 3 experiments, and error bars represent standard error of mean.

\section{Results}

Array analysis of miRNA changes during caloric restriction and fasting in mice

We detected global changes in miRNA expression using liver tissue from age-matched C57BL/6 J mice fed ad libitum (AL), 40\% calorically restricted (CR), or $24 \mathrm{~h}$ fasted (FA) mice analyzed by miRNA arrays. These arrays show significant alterations in miRNA expression (Fig. 1a-b) as well as a $73 \%$ overlap between $\mathrm{CR}$ and FA in the miRNAs changed (Fig. 1c). Multiple microRNAs belonging to the highly conserved miR-29 and miR-30 families showed significantly increased expression after exposure to both dietary interventions.

In order to analyze the effect of miRNAs with altered expression in both conditions we used Ingenuity Pathway analysis (IPA) software's miRNA target filter to identify experimentally observed targets reported in the literature. This list was filtered for miRNAs with detectable expression in mouse liver tissue in published arrays $[20,21]$. Core IPA analysis of the target list revealed that one of the top networks altered involved cell growth and proliferation centered on IGF1, EGF, and HGF growth factor signaling (Supplementary Figure 1). This is significant since many of the cancer prevention effects of $\mathrm{CR}$ are thought to involve repression of the pro-proliferation anti-apoptotic IGF$1 / \mathrm{AKT} / \mathrm{mTOR}$ signaling axis $[22,23]$.
CR increased expression of miR-29 and miR-30 family members and altered IGF-1 signaling in normal liver The microRNA prediction algorithm TargetScan v6.0 and IPA's miRNA target filter were utilized to identify predicted targets of the 26 microRNAs altered in both fasting and CR, yielding $>58,000$ predicted targets. To focus this search, we filtered this gene list for targets of miR-29 and miR-30 families that are known to be involved in IGF-1 signaling.

miR-29 represses p85 (PIK3R1) [24] and miR-30 targets JUN [25], both of which are important in cancer progression. We confirmed that multiple members of the IGF-1 signaling cascade, including pro-IGF-1, IGF$1 R$, IRS1, and phospho-Akt, are reduced in CR liver tissue (Fig. 2a). In CR and fasted tissue, IGF-1 and IGF-1R were reduced inversely to miR 29 and miR-30 expression as validated by qRT-PCR (Fig. 2a, b and c).

\section{CR increases miR-29 and miR-30 expression in primary breast tumor and liver tissue with metastases}

We assessed miR-29 and miR-30 expression in the primary breast tumor and liver tissue with breast cancer metastases of BALB/c mice fed AL or $30 \%$ reduced $\mathrm{CR}$ diets, to determine if $\mathrm{CR}$ effects the expression of these miRNAs. qRT-PCR was performed to survey miR-29 and miR-30 family member expression.CR increased miR-29b in the liver tissue by 2.5 -fold compared to AL (Fig. 2e(i)) with no change in expression in the tumor (Fig. 2d(i)). CR also increased the expression of miR-29c in the tumor and liver tissue by $\sim 3.4$-fold and $\sim 9$-fold respectively (Fig. 2d (ii) and Fig. 2e (ii)). CR caused a 3.5 -fold increase in the expression of miR-30a in tumor (Fig. 2d (iii)) and a 5-fold and 4-fold increase in miR-30b expression in tumor and liver tissue respectively (Fig. $2 \mathrm{~d}$ (iv) and 2E (iv)).

\section{Discussion}

Our initial hypothesis that microRNAs play a functional role in mediating the physiological effects of dietary restriction is supported by our observation of the changes in the unique global expression patterns of liver microRNAs of calorically restricted $(-40 \%)$ or $24-\mathrm{h}$ fasted C57BL/6 J mice compared to AL controls. It must also be noted that fasting produces $>2$ fold more alterations to microRNA expression than CR (71 vs. 38$)$. We predict that the larger group of miRNAs altered by fasting is due to an acute response, while expression changes 


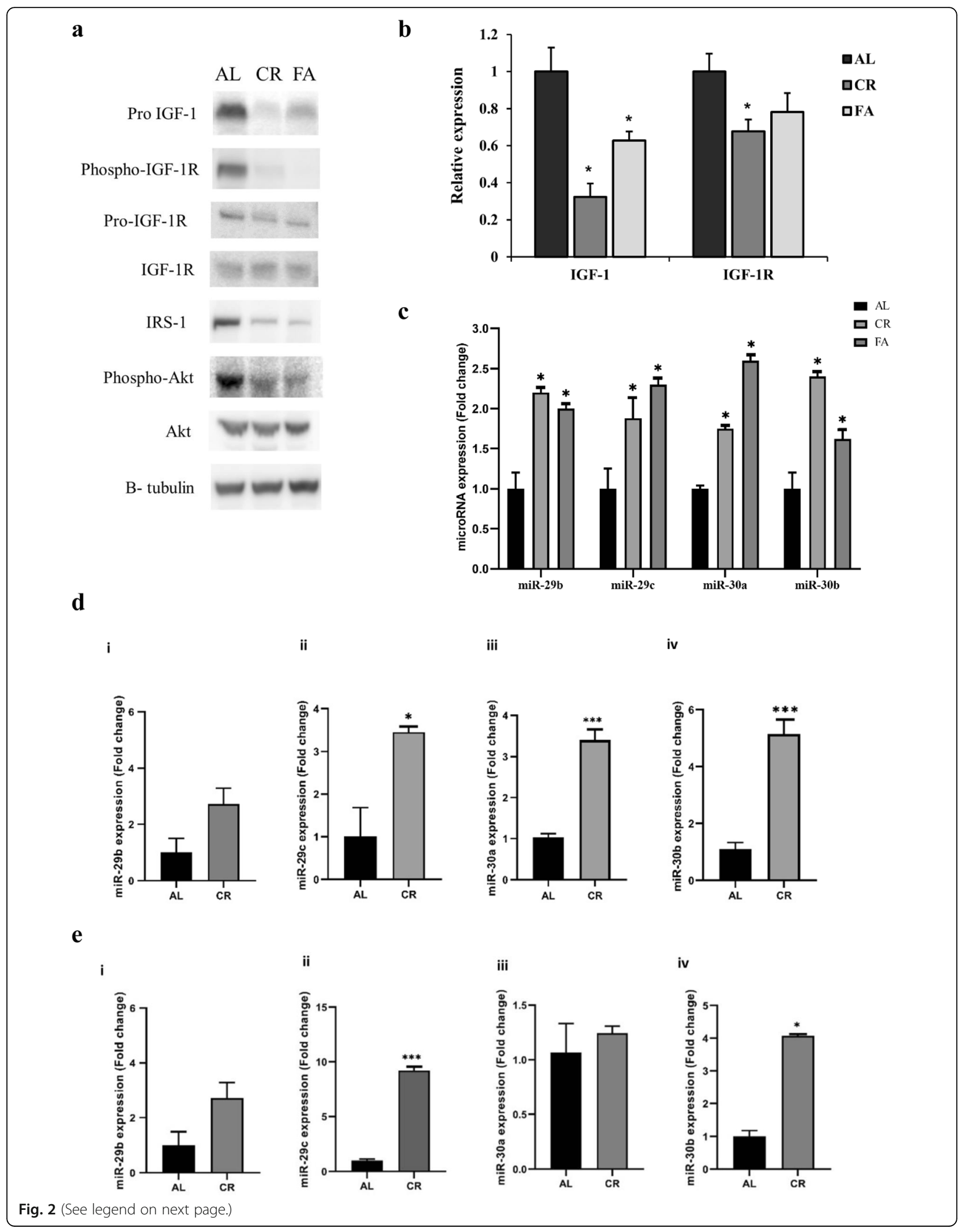


(See figure on previous page.)

Fig. 2 Diet modification using CR or FA repressed the IGF-1 pathway and altered the expression of miR-29 and miR-30. a Western blot analysis of IGF-1 pathway proteins from total protein purified from normal liver tissue of C57BL/6 J mice on AL, CR or FA diet. b qRT-PCR for expression of IGF-1 and IGF-1R in AL, CR, and FA normal liver tissue, mean \pm SD $\left({ }^{*}-p<0.05, n=4\right)$. c Real time qPCR validation of miR-29b, miR-29c, miR-30a and miR-30b expression in normal liver of mice on AL, CR or FA diets, mean \pm SD $\left({ }^{*}-p<0.05, n=4\right)$. $\mathbf{d}$ Expression of miR-29b (i), miR-29c (ii), miR$30 \mathrm{a}$ (iii) and miR-30b (iv) in primary breast cancer tumor of BALB/C mice on AL or CR (30\%) diet represented by mean \pm SE (***-p $<0.001$ and ${ }_{-}^{*}-p<0.05, n=3$ ). e Expression of miR-29b (i), miR-29c (ii), miR-30a (iii) and miR-30b (iv) in liver tissue with metastases of breast cancer in BALB/c mice on $\mathrm{AL}$ or $\mathrm{CR}$ diets, represented by mean $\pm \mathrm{SE}\left({ }^{* *}-p<0.001\right.$ and $\left.{ }^{*}-p<0.05, n=3\right)$

detected in the CR group represent stable changes due to longer-term dietary changes. However, $73 \%$ of the miRNA expression changes that were detected in the CR group were also altered in the fasted group, suggesting that they may be mechanistically important in pathways influenced by dietary alterations.

Systems analysis of experimentally reported targets of the group of miRNAs that were changed in both conditions using IPA software showed an enrichment in transcripts that, if repressed, would suppress several growth factor signaling pathways. This observation is in agreement with what is known in general about the cellular response to dietary restriction, whereby growth and reproduction is repressed in favor of maintenance and repair [26]. Expression of several family members of the miR-29 and miR-30 family was increased in both the fasted and CR tissues; and are associated with tumor suppressive processes. Specifically, the miR-29 family plays an inhibitory role in oncogenic metabolism affecting proliferation, angiogenesis, metastasis, and apoptosis. miR-29 has been shown to be tumor suppressive in more than $95 \%$ publications based on cancer studies [27]. Overexpression of miR-29a directly suppressed IGF-1R in the HepG2 Hepatocellular Carcinoma cellline [28]. Park et al. in an in vitro study showed that members of the miR-29 family repressed p85 $\alpha$ (PI3K) and upregulated p53 [24]. miR-30 family members act as both tumor suppressive and oncogenic miRNAs depending on the type of cancer. As a tumor suppressor in breast cancer, gastric cancer, pancreatic cancer and renal cell carcinoma, miR-30 prevents proliferation, invasion and metastasis [29-32] by targeting IGF-1R [31].

Many primary tumors spread to the liver, with greater than $50 \%$ of colorectal tumors metastasizing to the liver [2]. Other more common cancers that produce liver metastases include breast cancer, lung cancer and pancreatic cancer among others [32]. Since the members of the miR-29 and miR-30 family repress the IGF-1 signaling pathway, we explored the capacity of diet to alter metastatic tumor biology. CR increased the expression of miR-29b, miR-30a and miR-30b in the tumor, and increased expression of miR-29b, miR-29c and miR-30b in the liver tissue with metastases from breast tumor. We believe that alterations to miR-30a expression in primary breast cancers not observed in the liver are due to differences in the two environments that drive different expression pathways leading to miR-30 family expression. Here we show that CR leads to increased expression of miR-29 and miR-30 in the both the normal liver, primary breast tumor and liver with metastases from BC. Both these microRNAs repress IGF-1, while IGF-1R was a target of miR-30 alone. These findings are in agreement with our previous studies in an in vivo model of triple negative breast cancer (TNBC) that showed that at both the mRNA and protein level these genes are downregulated by $\mathrm{CR}$ alone or in combination with other treatments $[6,33]$. Diet modification has also been shown to downregulate the IGF-1 signaling in other cancers including prostate, pancreatic and colon cancer thereby delaying their progression [34-36]. Many studies have demonstrated the role of IGF-1/ IGF-1R signaling pathway in invasion and metastasis [37-39].

The liver produces $90 \%$ of all IGF-1 and we observe that CR represses IGF-1 and IGF-1R via regulation by miR-29 and miR-30. Taken together we hypothesize that $\mathrm{CR}$ combined with other treatment may be able to prevent progression of liver metastasis via the upregulation of miR-29 and miR-30 and downregulation of the IGF$1 / \mathrm{AKT} / \mathrm{mTOR}$ signaling pathway. Using a dietary intervention to downregulate the IGF-1 pathway could represent an ideal strategy to employ in clinical practice since the downregulation of this pathway is known to decrease cancer progression and metastases.

\section{Supplementary information}

Supplementary information accompanies this paper at https://doi.org/10. 1186/s12986-020-00437-z.

\section{Additional file 1.}

\section{Abbreviations}

AL: Ad. Libitum; CR: Calorie restriction; EGF: Epidermal growth factor; HGF: Hepatocyte growth factor; IGF-1: Insulin-like growth factor-1; IGF1R: Insulin-like growth factor-1 receptor; IPA: Ingenuity pathway analysis; miR, miRNA: microRNA; TNBC: Triple negative breast cancer

\section{Acknowledgements}

The authors would like to thank Charles Kivolowitz for helping us edit and revise the manuscript and other the members of the Simone lab for the helpful discussions.. The authors would also like to thank the Animal Care Facility at Thomas Jefferson University for their help throughout this study. 


\section{Authors' contributions}

Experiments were designed by AAS, AS, JS, KC and NLS. Experiments were performed by AAS, AS, JES, TD, KC and NLS. Data were analyzed by AAS, AS, JES, KC and NLS. Figures were generated and the manuscript was written by AAS, AS, JES, KC and NLS. All authors read, edited and approved the final manuscript.

\section{Funding}

This work was supported by R01CA227479 (NLS) and the NCl Cancer Center Grant P30CA056036 for supporting the Flow Cytometry, Translational Research/Pathology, and Lab Animals core facilities.

\section{Availability of data and materials}

All data generated or analyzed during this study are included in this published article (and its supplementary information files).

\section{Ethics approval and consent to participate}

The animal protocols were approved by the Institutional Animal Care and Use Committee at Thomas Jefferson University.

\section{Consent for publication}

Not Applicable.

\section{Competing interests}

The authors declare that they have no competing interests.

\section{Author details}

'Department of Radiation Oncology, Sidney Kimmel Cancer Center at Thomas Jefferson University, Philadelphia, PA, USA. ${ }^{2}$ Center for Cancer Research, National Cancer Institute, Bethesda, MD, USA.

\section{Received: 31 October 2019 Accepted: 27 February 2020}

\section{Published online: 23 March 2020}

\section{References}

1. Selzner M, Morse MA, Vredenburgh JJ, Meyers WC, Clavien PA. Liver metastases from breast cancer: long-term survival after curative resection. Surgery. 2000;127(4):383-9.

2. Zarour LR, Anand S, Billingsley KG, Bisson WH, Cercek A, Clarke MF, et al. Colorectal Cancer liver metastasis: evolving paradigms and future directions. Cell Mol Gastroenterol Hepatol. 2017;3(2):163-73.

3. Hagopian K, Ramsey JJ, Weindruch R. Caloric restriction increases gluconeogenic and transaminase enzyme activities in mouse liver. Exp Gerontol. 2003;38(3):267-78.

4. Hagopian K, Ramsey JJ, Weindruch R. Influence of age and caloric restriction on liver glycolytic enzyme activities and metabolite concentrations in mice. Exp Gerontol. 2003:38(3):253-66.

5. Larson-Meyer DE, Newcomer BR, Heilbronn LK, Volaufova J, Smith SR, Alfonso $\mathrm{A}$, et al. Effect of 6-month calorie restriction and exercise on serum and liver lipids and markers of liver function. Obesity (Silver Spring). 2008;16(6):1355-62.

6. Simone BA, Dan T, Palagani A, Jin L, Han SY, Wright C, et al. Caloric restriction coupled with radiation decreases metastatic burden in triple negative breast cancer. Cell Cycle. 2016;15(17):2265-74.

7. Thompson HJ, McTiernan A. Weight cycling and cancer: weighing the evidence of intermittent caloric restriction and cancer risk. Cancer Prev Res (Phila). 2011;4(11):1736-42.

8. Zhang LN, Mitchell SE, Hambly C, Morgan DG, Clapham JC, Speakman JR. Physiological and behavioral responses to intermittent starvation in C57BL/ 6J mice. Physiol Behav. 2012;105(2):376-87.

9. Singh R, Lakhanpal D, Kumar S, et al. Late-onset intermittent fasting dietary restriction as a potential intervention to retard age-associated brain function impairments in male rats. Age (Dordr). 2012;34(4):917-933.

10. Ha TY. MicroRNAs in human diseases: from autoimmune diseases to skin Psychiatric and Neurodegenerative Diseases. Immune Netw. 2011;11(5):227-44.

11. Belgardt BF, Ahmed K, Spranger M, Latreille M, Denzler R, Kondratiuk N, et al. The microRNA-200 family regulates pancreatic beta cell survival in type 2 diabetes. Nat Med. 2015;21(6):619-27.

12. Willeit $P$, Skroblin $P$, Moschen AR, Yin $X$, Kaudewitz D, Zampetaki A, et al. Circulating MicroRNA-122 is associated with the risk of new-onset metabolic syndrome and type 2 diabetes. Diabetes. 2017;66(2):347-57.
13. Navickas R, Gal D, Laucevicius A, Taparauskaite A, Zdanyte M, Holvoet P. Identifying circulating microRNAs as biomarkers of cardiovascular disease: a systematic review. Cardiovasc Res. 2016;111(4):322-37.

14. Iorio MV, Croce CM. MicroRNA dysregulation in cancer: diagnostics, monitoring and therapeutics. A comprehensive review. EMBO Mol Med. 2012:4(3):143-59.

15. Smith-Vikos T, Slack FJ. MicroRNAs and their roles in aging. I Cell Sci. 2012; 125(Pt 1):7-17.

16. Olivo-Marston SE, Hursting SD, Perkins SN, Schetter A, Khan M, Croce C, et al. Effects of calorie restriction and diet-induced obesity on murine colon carcinogenesis, growth and inflammatory factors, and microRNA expression. PLoS One. 2014;9(4):e94765.

17. Palmer JD, Soule BP, Simone BA, Zaorsky NG, Jin L, Simone NL. MicroRNA expression altered by diet: can food be medicinal? Ageing Res Rev. 2014;17:16-24.

18. lacomino G, Siani A. Role of microRNAs in obesity and obesity-related diseases. Genes Nutr. 2017;12:23.

19. Simone NL, Soule BP, Ly D, Saleh AD, Savage JE, Degraff W, et al. lonizing radiationinduced oxidative stress alters miRNA expression. PLoS One. 2009;4(7):e6377.

20. Massip L, Garand C, Paquet ER, Cogger VC, O'Reilly JN, Tworek L, et al. Vitamin $C$ restores healthy aging in a mouse model for Werner syndrome. FASEB J. 2010:24(1):158-72.

21. Swindell WR. Comparative analysis of microarray data identifies common responses to caloric restriction among mouse tissues. Mech Ageing Dev. 2008;129(3):138-53.

22. Patel AC, Nunez NP, Perkins SN, Barrett JC, Hursting SD. Effects of energy balance on cancer in genetically altered mice. J Nutr. 2004;134(12 Suppl):3394S-8S,

23. Salminen A, Kaarniranta K. Insulin/IGF-1 paradox of aging: regulation via AKT/IKK/NF-kappaB signaling. Cell Signal. 2010;22(4):573-7.

24. Park SY, Lee JH, Ha M, Nam JW, Kim VN. miR-29 miRNAs activate $\mathrm{p} 53$ by targeting p85 alpha and CDC42. Nat Struct Mol Biol. 2009;16(1):23-9.

25. Selbach M, Schwanhausser B, Thierfelder N, Fang Z, Khanin R, Rajewsky N. Widespread changes in protein synthesis induced by microRNAs. Nature. 2008;455(7209):58-63.

26. Kirkwood TB, Shanley DP. Food restriction, evolution and ageing. Mech Ageing Dev. 2005;126(9):1011-6.

27. Kwon JJ, Factora TD, Dey S, Kota J. A systematic review of miR-29 in Cancer. Mol Ther Oncolytics. 2019;12:173-94.

28. Wang X, Liu S, Cao L, Zhang T, Yue D, Wang L, et al. miR-29a-3p suppresses cell proliferation and migration by downregulating IGF1R in hepatocellular carcinoma. Oncotarget. 2017:8(49):86592-603.

29. Liu W, Li H, Wang Y, Zhao X, Guo Y, Jin J, et al. MiR-30b-5p functions as a tumor suppressor in cell proliferation, metastasis and epithelial-tomesenchymal transition by targeting $\mathrm{G}$-protein subunit alpha-13 in renal cell carcinoma. Gene. 2017;626:275-81.

30. Xiong $Y$, Wang $Y$, Wang $L$, Huang $Y, X u Y, X u L$, et al. MicroRNA-30b targets snail to impede epithelial-mesenchymal transition in pancreatic cancer stem cells. J Cancer. 2018:9(12):2147-59.

31. Liu $Y$, Zhou $Y$, Gong $X$, Zhang C. MicroRNA-30a-5p inhibits the proliferation and invasion of gastric cancer cells by targeting insulin-like growth factor 1 receptor. Exp Ther Med. 2017;14(1):173-80.

32. Croset M, Pantano F, Kan CWS, Bonnelye E, Descotes F, Alix-Panabieres C, et al. miRNA-30 family members inhibit breast Cancer invasion, Osteomimicry, and bone destruction by directly targeting multiple bone metastasis-associated genes. Cancer Res. 2018;78(18):5259-73.

33. Simone BA, Palagani A, Strickland K, Ko K, Jin L, Lim MK, et al. Caloric restriction counteracts chemotherapy-induced inflammation and increases response to therapy in a triple negative breast cancer model. Cell Cycle. 2018;17(13):1536-44.

34. O'Flanagan CH, Smith LA, McDonell SB, Hursting SD. When less may be more: calorie restriction and response to cancer therapy. BMC Med. 2017;15(1):106.

35. Lashinger LM, Malone LM, McArthur MJ, Goldberg JA, Daniels EA, Pavone A, et al. Genetic reduction of insulin-like growth factor-1 mimics the anticancer effects of calorie restriction on cyclooxygenase-2-driven pancreatic neoplasia. Cancer Prev Res (Phila). 2011;4(7):1030-40.

36. Galet C, Gray A, Said JW, Castor B, Wan J, Beltran PJ, et al. Effects of calorie restriction and IGF-1 receptor blockade on the progression of 22Rv1 prostate cancer xenografts. Int J Mol Sci. 2013;14(7):13782-95.

37. Weroha SJ, Haluska P. The insulin-like growth factor system in cancer Endocrinol Metab Clin N Am. 2012:41(2):335-50 vi.

38. Lei T, Ling X. IGF-1 promotes the growth and metastasis of hepatocellular carcinoma via the inhibition of proteasome-mediated cathepsin B degradation. World J Gastroenterol. 2015;21(35):10137-49. 
39. Bahr C, Groner B. The IGF-1 receptor and its contributions to metastatic tumor growth-novel approaches to the inhibition of IGF-1R function. Growth Factors. 2005;23(1):1-14.

\section{Publisher's Note}

Springer Nature remains neutral with regard to jurisdictional claims in published maps and institutional affiliations.

Ready to submit your research? Choose BMC and benefit from:

- fast, convenient online submission

- thorough peer review by experienced researchers in your field

- rapid publication on acceptance

- support for research data, including large and complex data types

- gold Open Access which fosters wider collaboration and increased citations

- maximum visibility for your research: over $100 \mathrm{M}$ website views per year

At BMC, research is always in progress. 